\title{
A young lady with dysphagia
}

\author{
Seng Wee Cheo, Woh Wei Mak, Qin Jian Low
}

Cheo SW, Mak WW, Low QJ. A young lady with dysphagia. Malays Fam Physician. 2021;16(2);98-101. https://doi.org/10.51866/tyk1120

\section{Keywords:}

Dysphagia, achalasia cardia, chest radiograph

\section{Authors:}

\section{Cheo Seng Wee}

(Corresponding author)

MRCP (UK)

Department of Internal Medicine

Hospital Lahad Datu, Peti Surat 60065

Lahad Datu, Sabah, Malaysia

Email: cheosengwee@gmail.com

Mak Woh Wei

MRCP (UK)

Department of Internal Medicine

Hospital Bentong, Ministry of Health

Malaysia, Jalan Tras, Darul Makmur

Bentong, Pahang

\section{Low Qin Jian}

MRCP (UK)

Department of Internal Medicine

Hospital Sultanah Nora Ismail, Jalan

Korma, Taman Soga, Batu Pahat

Johor, Malaysia

\begin{abstract}
Chest radiograph is one of the most commonly employed imaging modalities in primary care. It may be done for symptomatic patients or routine health screening. Hence, it is important for a primary care physician to be able to interpret chest radiograph systematically in relation to patient's clinical history. Here, we would like to illustrate a case of abnormal chest radiograph detected during health screening.
\end{abstract}

\section{Introduction}

Chest radiograph is one of the most commonly used diagnostic modalities in primary care. It is usually done for various reasons, such as chronic cough, dyspnoea and fever. Doctors in primary care will need to evaluate and interpret a chest radiograph correctly in order to identify the underlying problem. Interpretation of chest radiograph will also need to incorporate the clinical history of the patient. In this present case, we would like to illustrate a young lady with an abnormal chest radiograph detected during health screening.

\section{Case Presentation}

A 31-year-old lady with no past medical illness was noted to have an abnormal chest radiograph during health screening in a health clinic. She denied chest pain, dyspnoea, orthopnoea or reduced effort tolerance. She also did not complain of cough or fever. Further history revealed that she had experienced regurgitation and dysphagia for the past two years, initially with solid food and then with liquid. The regurgitation usually occurred 20 minutes after a meal. There was also a loss of weight with normal appetite. She denied symptoms of scleroderma or muscle weakness, and her family history was negative for any malignancy or neuromuscular disorder.

On examination, she was well built. Her blood pressure was $125 / 76 \mathrm{mmHg}$, pulse rate was 75 beats per minute and her temperature was afebrile. Cardiovascular examination revealed dual rhythm and no murmur. Respiratory and abdomen examinations were normal and there were no features of scleroderma or myasthenia gravis. All four limbs exhibited normal power. Her baseline full blood count, renal profile and liver function test were all normal and her electrocardiogram showed normal sinus rhythm. A chest radiograph was done (Figure 1).

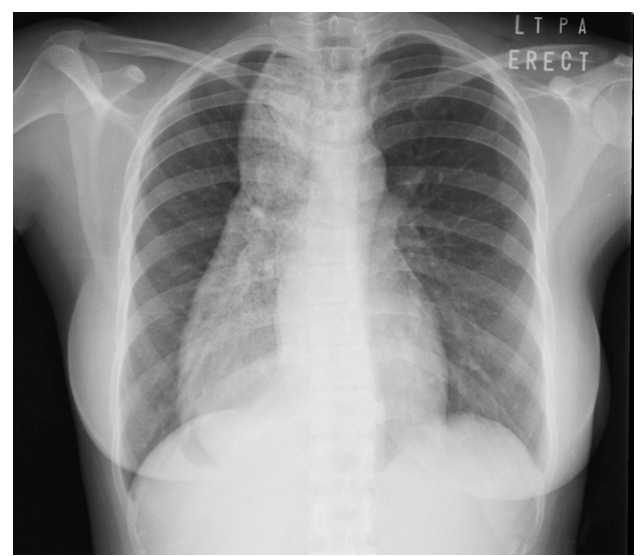

Figure 1

\section{Questions and Answers:}

\section{Describe the chest radiograph.}

This is the PA erect view chest radiograph of the patient, which showed a well-defined heterogenous tubular opacity occupying the mediastinum. There was absence of any gastric bubble, but presence of a cervicothoracic sign (Figure 2), which refers to visualisation of a lesion above the level of the clavicle, indicating the abnormality is located posteriorly. Other structures such as lung field, ribs and heart appear normal. 


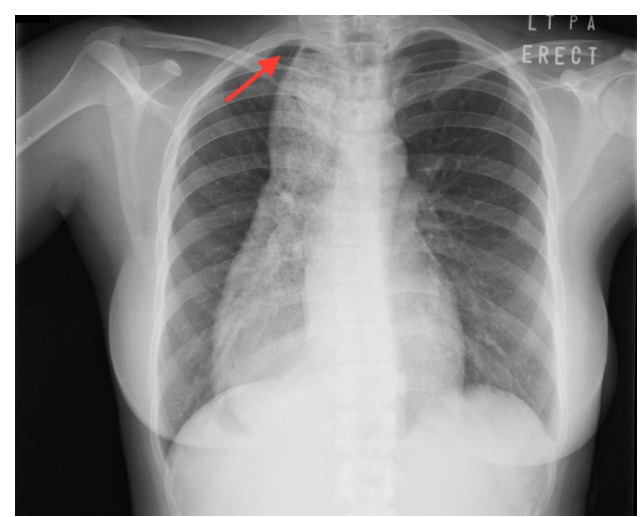

Figure 2: Chest radiograph of 31-year-old woman showing well-defined heterogenous tubular opacity occupying the mediastinum. There is absence of gastric bubble. Arrow depicts cervicothoracic sign.

\section{What is the most likely diagnosis and differential diagnoses?}

The most likely diagnosis is achalasia cardia. This diagnosis is based on the clinical history of a young patient with dysphagia to solid and then liquid food and typical chest radiograph findings. The differential diagnoses to be considered include oesophageal stricture, oesophageal carcinoma, mitral stenosis, retrosternal goiter and mediastinal mass, such as thymoma or lymphadenopathy.

\section{What other investigations can be done?}

a) Echocardiography - to exclude any cardiac abnormalities such as mitral stenosis, which may cause dysphagia in a young patient.

b) Barium swallow - may be used to confirm oesophagus dilatation. Bird beak sign can be seen in achalasia cardia.

c) Computed tomography (CT) of thorax - to further evaluate the chest radiograph abnormality. CT thorax will give a clearer view of oesophagus. CT scan is more useful to assess complication of achalasia. In addition, CT thorax is also used to rule out gastro-esophageal malignancy if oesophagogastroduodenoscopy (OGDS) cannot traverse the lower oesophagogastric junction. ${ }^{10}$

d) OGDS - to look for features of achalasia and exclude malignancy.

e) High resolution manometry - to confirm the diagnosis of achalasia cardia after OGDS and barium swallow.

\section{Outline the management plan.}

Patient should be referred for OGDS and further investigations to confirm the diagnosis of achalasia. Once diagnosis is confirmed, patient can be offered per-oral endoscopic myotomy (POEM).

\section{Case Progress}

Coming back to our case, the patient's chest radiograph showed well-defined tubular heterogenous opacity at the mediastinum with absent gastric bubble. Echocardiogram was normal with normal heart chamber. A diagnosis of achalasia cardia was suspected.

Subsequently, she underwent CT thorax, which showed the oesophagus to be grossly dilated throughout its entire length, with its widest diameter measured at $6.8 \mathrm{~cm}$ (Figure 3). There were no secondary causes found. OGDS showed megaesophagus, with presence of food particles in the oesophagus. The patient was diagnosed with achalasia cardia. She was then sent for manometry in a tertiary centre, with a planned treatment of POEM.

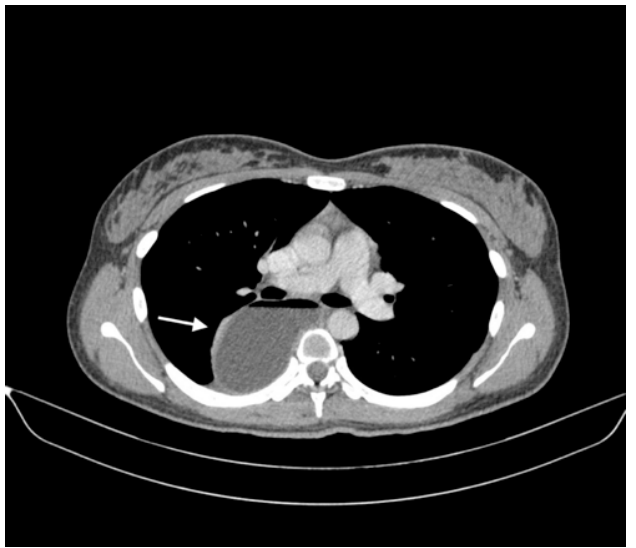

Figure 3: Computed tomography of thorax of 31-year-old woman showing dilated oesophagus with air fluid level.

\section{Discussion}

Achalasia cardia is an oesophageal motility disorder, where there is incomplete relaxation of the lower oesophageal sphincter (LES) and loss of oesophageal peristalsis. ${ }^{1}$ It is a rare condition, with an annual incidence of approximately 1.6 cases per 100,000 individuals and a prevalence of 10 cases per 100,000 individuals. $^{2}$ Its onset is typically at a younger age and is usually insidiouspatients often seek medical attention after many years of symptoms. In one series of 87 consecutive patients with newly diagnosed achalasia, the mean duration of symptoms was 4.7 years prior to the diagnosis. ${ }^{3}$ This 
long time to diagnosis is possibly due to misinterpretation of typical findings caused by a lack of awareness among doctors regarding the spectrum of symptoms of achalasia, which is more likely than atypical presentations being a contributing factor. ${ }^{3}$ The symptoms may also sometimes be misinterpreted as gastroesophageal reflux. ${ }^{4}$

In approaching any chest radiograph, we should adopt an approach of $\mathrm{ABC}$, where $\mathrm{A}$ is airway (trachea, lung, pleura), B is bones and $\mathrm{C}$ is circulation (heart, mediastinum, vascular marking). ${ }^{5}$ In the chest radiograph presented above, there is a well-defined tubular heterogenous opacity arising from the mediastinum. The presence of a cervicothoracic sign indicates that the opacity is arising from the posterior mediastinum. ${ }^{6}$ Presence of heterogeneity in the opacity excludes vascular structure. There is also absence of gastric bubble. Overall, this is suggestive of achalasia cardia.

Diagnosis of achalasia cardia requires good clinical evaluation paired with diagnostic imaging. The cardinal symptom of achalasia is dysphagia to solid food and liquids, which is seen in more than $95 \%$ of patients. ${ }^{7}$ As a result of the failure of the LES to relax, patients will experience regurgitation of food, weight loss, chest pain and chest discomfort. Occasionally, some patients may complain of hiccups and retrosternal heartburn that mimics gastroesophageal reflux disease. ${ }^{8}$

Apart from chest radiographs, other diagnostic modalities include barium swallow, upper endoscopy and manometry.? Barium swallow typically shows a bird-beak appearance. In
OGDS, this may reveal a dilated oesophagus with residual food particles and a contracted LES. In achalasia, the contracted LES can usually be traversed easily with gentle pressure on the endoscope. ${ }^{10}$ Difficulty in traversing the esophagogastric junction by OGDS due to firm resistance should raise the suspicion of neoplastic infiltration or other causes of pseudoachalasia. ${ }^{11}$ Further testing with endoscopic ultrasound or CT scan to rule out malignancy is then warranted. Manometry typically demonstrates high LES pressure. Diagnosis can be made by high resolution oesophageal manometry after OGDS and barium swallow.

In terms of treatment, conventional therapies include pharmacological therapy, botulinum toxin injection, pneumatic dilatation and surgical myotomy. The use of botulinum toxin is quite limited as there is a lack of long-term efficacy, with recurrence rates of approximately $50 \%$ after one year and universal symptomatic relapse at two years. ${ }^{12}$ Pneumatic dilatation, done using a balloon to dilate the LES to weaken it, is a safe and efficient non-surgical therapy with good outcomes. ${ }^{13}$ In recent years, however, a paradigm shift has occurred concerning treatment of achalasia cardia with the introduction of POEM. ${ }^{14}$ All in all, the treatment of patients with achalasia should be individualised.

\section{Conflicts of Interest}

The author declared that they have no conflicts of interest.

\section{Funding}

The author received no financial support for this publication.

\section{How does this paper make a difference to general practice?}

Chest radiograph is a common investigation used in general practice. As medical practitioners, we must be able to interpret chest radiographs systematically in order to obtain a diagnosis. Through this case, we hope to illustrate the importance of a systematic approach to reading chest radiographs and the importance of clinical correlation. In addition, this case illustrates the importance of recognising the cervicothoracic sign, as its recognition will enable earlier diagnosis of achalasia cardia.

\section{References}

1. Sarumpaet F, Dairi L. A case report of achalasia. IOP Conf. Series: Earth and Environmental Science 125 (2018) 012209 doi :10.1088/1755-1315/125/1/012209
2. Sadowski DC, Ackah F, Jiang B, Svenson LW. Achalasia: Incidence, prevalence and survival. A population-based study. Neurogastroenterol Motil. 2010; 22(9):e256-e261. doi:10.1111/ j.1365-2982.2010.01511.x
3. Eckardt VF, Köhne U, Junginger T, Westermeier T. Risk factors for diagnostic delay in achalasia. Dig Dis Sci. 1997; 42(3):580-585. doi:10.1023/a:1018855327960 
4. Jeon HH, Kim J, Youn YH, Park H, Conklin JL. Clinical characteristics of patients with untreated achalasia. J Neurogastroenterol Motil. 2017; 23:378-384. https://doi.org/10.5056/ jnm16177 4

5. Puddy E, Hill C. Interpretation of the chest radiograph. Contin Educ Anaesth Crit Care Pain. 2007; 7(3):71-75. https://doi. org/10.1093/bjaceaccp/mkm014 5

6. Kumaresh A, Kumar M, Dev B, Gorantla R, Venkata Sai PM, Thanasekaraan V. Back to basics - 'Must know' classical signs in thoracic radiology.

J Clin Imaging Sci. 2015; 5:43- 6

7. Eckardt AJ, Eckardt VF. Current clinical approach to achalasia. World J Gastroenterol. 2009; 15(32):3969-3975. doi:10.3748/ wjg. 15.39697

8. Seeman H, Traube M. Hiccups and achalasia [published correction appears in Ann Intern Med. 1991; 115(12):986]. Ann Intern Med. 1991; 115(9):711-712. doi:10.7326/00034819-115-9-711 8
9. Niebisch S, Hadzijusufovic E, Mehdorn M, Müller M, Scheuermann U, Lyros O, Schulz HG, Jansen-Winkeln B, Lang H, Gockel I. Achalasia-An unnecessary long way to diagnosis. Dis Esophagus. 2017; 30(5):1-6. https://doi.org/10.1093/dote/dow004 9

10. Paterson WG, Goyal RJ, Habib FI. Esophageal motility disorders. GI Motility online 2006 doi:10.1038/gimo20. Cited 2 Jun 2006. Available from URL: http://www. nature.com/gimo/contents/pt1/ full/gimo20. html 10

11. Gockel I, Eckardt VF, Schmitt T, Junginger T. Pseudoachalasia: A case series and analysis of the literature. Scand J Gastroenterol. 2005; 40(4):378-385. doi:10.1080/00365520510012118 11

12. Boeckxstaens GE. Achalasia. Best Pract Res Clin Gastroenterol. 2007; 21(4):595-608. doi:10.1016/j.bpg.2007.03.004 12
13. Chuah SK, Wu KL, Hu TH, Tai WC, Changchien CS. Endoscope-guided pneumatic dilation for treatment of esophageal achalasia. World J Gastroenterol. 2010; 16(4):411-417. doi:10.3748/wjg.v16.i4.411 13

14. Ramchandani M, Nageshwar Reddy D, Nabi Z, Chavan R, Bapaye A, Bhatia S, Mehta N, Dhawan P, Chaudhary A, Ghoshal UC, Philip M, Neuhaus H, Deviere J, Inoue H. Management of achalasia cardia: Expert consensus statements. J Gastroenterol Hepatol. 2018; 33:1436-1444. https://doi.org/10.1111/ jgh.14097. 14 